\title{
BMJ Open Sickness absence and return to work among Japanese stroke survivors: a 365-day cohort study
}

\author{
Motoki Endo, ${ }^{1}$ Toshimi Sairenchi, ${ }^{2}$ Noriko Kojimahara, ${ }^{3}$ Yasuo Haruyama, ${ }^{2}$ \\ Yasuto Sato, ${ }^{3}$ Rika Kato, ${ }^{4}$ Naohito Yamaguchi ${ }^{3}$
}

To cite: Endo M, Sairenchi T, Kojimahara N, et al. Sickness absence and return to work among Japanese stroke survivors: a 365-day cohort study. BMJ Open 2016;6: e009682. doi:10.1136/ bmjopen-2015-009682

- Prepublication history for this paper is available online. To view these files please visit the journal online (http://dx.doi.org/10.1136/ bmjopen-2015-009682).

Received 22 August 2015 Revised 23 October 2015 Accepted 11 November 2015

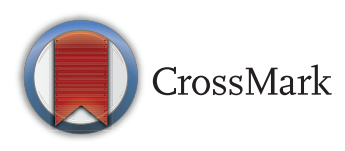

${ }^{1}$ Department of Public Health, Tokyo Women's Medical University, Tokyo, Japan ${ }^{2}$ Department of Public Health, Dokkyo Medical University, Mibu Town, Japan

${ }^{3}$ Department of Public Health, Tokyo Women's Medical University, Tokyo, Japan ${ }^{4}$ Oyama Health Management Center, Health Promotion Center, Komatsu Ltd, Oyama City, Japan

\footnotetext{
Correspondence to

Dr Motoki Endo;

m-endou@research.twmu. ac.jp
}

\section{ABSTRACT}

Objectives: The objective of this study was to investigate the cumulative return to work (RTW) rate and to clarify the predictors of the time to full-time RTW (full RTW) and resignation among Japanese stroke survivors, within the 365-day period following their initial day of sickness absence due to stroke.

Setting: This study was based on tertiary prevention of occupational health in large-scaled Japanese companies of various industries.

Participants: The participants in this study were 382 Japanese workers who experienced an episode of sickness leave due to clinically certified stroke diagnosed between 1 January 2000 and 31 December 2011. Data were obtained from an occupational health register. Participants were followed up for 365 days after the start day of the first sickness absence. The cumulative RTW rates by Kaplan-Meier estimates and predictors for time to full RTW and resignation by Cox regression were calculated.

Results: A total of 382 employees had their first sickness absence due to stroke during the 12-year follow-up period. The cumulative full RTW rates at 60 , 120, 180 and 365 days were $15.1 \%, 33.6 \%, 43.5 \%$ and $62.4 \%$, respectively. Employees who took sick leave due to cerebral haemorrhage had a longer time to full RTW (HR, $0.50 ; 95 \% \mathrm{Cl} 0.36$ to 0.69 ) than those with cerebral infarction. Older employees (over 50 years of age) demonstrated a shorter time to resignation than younger employees (HR, 3.30; $95 \% \mathrm{Cl} 1.17$ to 9.33 ). Manual workers had a longer time to resignation than non-manual workers (HR, $0.24 ; 95 \% \mathrm{Cl} 0.07$ to 0.78 ).

Conclusions: Cumulative RTW rates depended on the subtype of stroke, and older age was a predictor of resignation.

\section{INTRODUCTION}

Stroke is recognised as the single largest cause of severe disability worldwide ${ }^{1-4}$ and, in Japan, it is the number one cause of individuals becoming bedridden ${ }^{5}{ }^{6}$ despite its incidence and mortality declining substantially.

\section{Strengths and limitations of this study}

- The present study involved enrolment of a large number of participants ( 400 Japanese stroke survivors) and the follow-up rate was high.

- We used an objective measurement of sickness absence; the present study was based on data from clinically certified sickness absence using physicians' certificates.

- The participants did not include employees working in small-sized and medium-sized enterprises, which raises a question about the representativeness of the stroke survivors.

Stroke is a source of major disability, particularly in older workers, and is also associated with substantial socioeconomic burden; approximately $20 \%$ of stroke survivors belong to the working-age group in

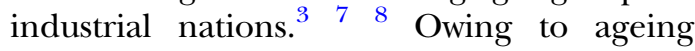
populations and prolonged stroke survival, the prevalence of stroke survivors within the working-age group is expected to increase in the near future. ${ }^{1} 4$ 9-11 Stroke at a younger age causes a disproportionate burden due to direct costs of providing medical care to the patient as well as indirect costs associated with lost productivity. ${ }^{41213}$ This is not only an individual loss, but an economic burden to society, as the expected duration of sickness absence is high in these younger patients. ${ }^{14} 15$ Return to work (RTW) after stroke has become increasingly important as a stroke-related outcome in occupational health services as well as in community-based rehabilitation, ${ }^{3}{ }^{16-18}$ and promoting early RTW after stroke may help reduce indirect costs that, for example, are associated with lost productivity for companies. ${ }^{19}$

In order to offer effective occupational rehabilitation for stroke survivors, it is very important to identify what kind of stroke survivors have a higher likelihood of RTW, and what is modifiable through rehabilitation. ${ }^{11}$ 
An analysis of occupational outcome after stroke needs to be adjusted for several influential factors, including demographics and occupational status. ${ }^{20}$ However, to the best of our knowledge, there has been no workforcebased Japanese study investigating the cumulative RTW rate after the first sickness absence due to stroke, and information on how sick absence varies by type of stroke would be valuable. ${ }^{21}$ This research will also better inform stroke survivors on their choices and future plan of work; some patients may try to RTW, and others may decide not to.

The objective of this study was to clarify the predictors of the time to full-time RTW (full RTW) and resignation among Japanese stroke survivors, within the 365-day period following their initial day of sickness absence due to stroke. Furthermore, this study may help companies establish or improve their RTW support systems for stroke survivors, and these improved healthcare policies may provide greater support and satisfaction to stroke survivors and their families. ${ }^{13}$

\section{METHODS}

\section{Participants}

This study was based on retrospective evaluation of a workforce-based cohort on the course of sickness absence among stroke survivors. Registered data of sickness absence were obtained from a private occupational health centre comprised of approximately 30 occupational physicians (OPs) and 75 occupational health nurses. These OPs were contracted to 35 large-scaled Japanese companies of various industries (telecommunications, logistics, energy, construction, etc), to provide their employees with occupational health services. About 68000 employees were working for these companies on a full-time basis from 2000 to 2011. Anonymous data were received from the private occupational health centre. During data collection, informed consent was not obtained from all participants as data were anonymous.

The occupational health service registration system of sickness absence and RTW was as follows: after having a stroke, an employee was required to certify an episode of sickness absence by submitting a physician's certificate stating that the employee was unable to work. After confirmation of the medical validity of the issued physician's certificate by the OP, the human resources department registered the data of only full-time workers. The OPs recorded the causes of sickness absence referring to the WHO's International Classification of Diseases, 10th Revision (ICD-10). For RTW, employees were required to submit a physician's certificate stating that they were fit for RTW, as well as to participate in interviews with their company's respective OPs for further confirmation that RTW was medically acceptable. OPs further determined whether the employee in question could full RTW or part time RTW (partial RTW, usually $4-6 \mathrm{~h}$ a day), and issued the OP's RTW certificate to the company.
We defined stroke subtypes as 'cerebral infarction (I63)', 'cerebral haemorrhage (I61)' and 'subarachnoid haemorrhage (I60)', according to ICD-10. Employees who experienced an episode of sickness absence due to stroke between 1 January 2000 and 31 December 2011 were included in this study. During this 12-year period, 382 employees had a stroke.

\section{Statistical analysis}

Participant outcomes within the 365-day period following their initial day of sickness absence were obtained from the register and utilised for this study. Kaplan-Meier curves were computed to illustrate the outcome of sickness absence according to stroke subtype after a 365-day period following the initial day of sickness absence. Participants were classified into four categories; 'died', 'resigned', 'disabled' and 'RTW'. 'Disabled' was defined as participants who remained absent due to illness by the end of the 365-day period. The number of participants were counted for each outcome using the first sickness absence due to stroke. The cumulative rate of RTW was measured at 60 (2 months), 120 (4 months), 180 (6 months) and 365 days (12 months) after the first day of sickness absence, using Kaplan-Meier analysis.

To identify predictors of RTW, we used a Cox proportional hazard model for survival analysis. Time of follow-up was calculated from the start date of sickness absence to either RTW or 365 days after, whichever came first. Those who died were categorised as 'no RTW after 365 days', and stroke survivors who resigned were right censored starting the day they resigned. A HR of more than 1 meant a shorter time to full RTW and a reduced duration of sickness absence until full RTW, compared with the reference. A HR of less than 1 meant a longer time to full RTW.

Similarly, predictors of resignation were also analysed by a Cox proportional hazard model. Those who died were categorised as 'no RTW after 365 days', and stroke survivors who resigned were right censored starting the day they resigned. A HR of more than 1 meant a shorter time to resignation, and vice versa. Job title was divided into two groups: 'desk worker' (eg, 'office worker', 'sales worker', 'researcher'), which involves a mainly mental workload, and 'manual worker' (eg, 'technician'), which involves a mainly physical workload. A 'manager' was defined as an individual who belonged to an administrative post, which in Japanese organisations is considered to be a position higher than a section chief.

Statistical analysis was performed using SPSS for Windows V.21.

\section{RESULTS}

During the study period, 382 employees experienced their first episode of sickness absence due to stroke certified by their physicians. The follow-up rate of this study was $99.5 \%$ ( 2 stroke survivors were lost to follow-up). 
Table 1 shows the basic characteristics of the stroke survivors: of 380 participants, $332(87.3 \%)$ were male and $48(12.7 \%)$ were female, mean age at the initial day of sickness absence was 52.7 years.

The median duration of sickness absence until either partial or full RTW was 106 days ( 3 months). The median duration until full RTW was 259 days ( $\sim 8$ months). In the 365-day period following the initial day of sickness absence, 26 participants had resigned from their place of employment, 9 participants had died and 62 participants had been classified as 'disabled', or unable to RTW within the 365-day period.

The Kaplan-Meier survival analysis demonstrated probability of RTW after sick leave over time until day of full RTW. The cumulative full RTW rates at 60, 120, 180 and 365 days were $15.1 \%, 33.6 \%, 43.5 \%$ and $62.4 \%$, respectively.

Univariate and multivariable analysis for predictors of RTW using Cox regression models (model 1, full model; model 2, stepwise model; model 3, stepwise model plus age and sex) are shown in table 2.

Participants in the 'manager' group tended to have a shorter time until full RTW. In the stepwise model (model 2), the 'manager' HR for time to full RTW was 1.71 (95\% CI 1.04 to 2.82) compared with 'nonmanagers'. Employees experiencing sickness absence due to cerebral haemorrhage had a longer time to full RTW (HR, 0.50; 95\% CI 0.36 to 0.69 ) than those with cerebral infarction, while subarachnoid haemorrhage compared with cerebral infarction was not statistically associated with a longer time.

Similarly, univariate and multivariable analysis for predictors of resignation using Cox regression models (model 1, full model; model 2, stepwise model; model 3, stepwise model plus sex) are shown in table 3 .

Older participants (50 years and older) had a shorter time to resignation than younger participants (HR, 3.30; 95\% CI 1.17 to 9.33 ). Manual workers had a longer time to resignation than non-manual workers (HR, 0.24; $95 \%$ CI 0.07 to 0.78 ).

\section{DISCUSSION}

To the best of our knowledge, the present study is the first workforce-based Japanese study showing the cumulative RTW rates and analysing the predictor of the time to full RTW and resignation among stroke survivors by using survival analysis.

The present study showed that the cumulative full RTW rate 365 days after onset of stroke was $62.4 \%$, similar to other studies (reporting $60 \%$ by 365 days). ${ }^{19} 22{ }^{23}$ However, the RTW rate reported in a UK study was $35 \%$, which is relatively lower than in the present study. ${ }^{24}$ A cohort study from Denmark showed that the odds for return to gainful occupation 2 years after stroke tended to increase-from 54\% in 1996 to $72 \%$ in $2006 .^{25}$ Across the stroke survivor RTW studies, the mean RTW rate has been $44 \%{ }^{26}$ These differences in RTW rates among the different studies may be explained by differences in company healthcare systems, participants, study design and methodologies, and an overall RTW rate after stroke cannot be reliably estimated. $^{1622} 2426-28$

The median time to partial or full RTW among total participants was approximately 3 months.

The rate of RTW declined over time after the initial day of sickness absence; the RTW rate was highest in the first quarter of the year, followed by the second quarter, a tendency in accordance with previous studies. ${ }^{19}$ This may be due to the shape of the distribution of sickness absence, which has been reported to be heavily right-skewed. $^{29} 30$

Few studies have investigated the predictors of RTW and the differences in cumulative RTW rates among the different stroke subtypes. ${ }^{21}$ According to Cox regression analysis, the present study showed that patients with cerebral infarction returned to work earlier than patients with cerebral haemorrhage, which was consistent with findings in a previous study. ${ }^{18}$ Peter et al pointed out that patients with cerebral haemorrhage tended to have greater functional impairment than those with cerebral infarction. ${ }^{31}$

The present RTW rate of patients with cerebral infarction was approximately the same as in previous studies, which reported that approximately $70 \%$ of patients with cerebral infarction had returned to work, though frequently with depressive symptoms. ${ }^{21}$ In another study, approximately $70 \%$ of subarachnoid haemorrhage survivors returned to work, in line with the present results. ${ }^{32}$ 'Manager' group participants tended to have shorter time to full RTW than 'non-manager'. To our knowledge, there are few stroke survivors' studies investigating the position of 'manager' as a predictor of RTW. Previous studies showed that managers returned to work earlier than other workers in elementary occupations, yet a different study showed that 'manager' was not significantly associated with time to RTW. ${ }^{11}{ }^{18}$ In one study, among managers, the RTW rate in those with more work-related stress was shown to be higher. ${ }^{33}$ It was hypothesised that, among managers, with more important occupational positions comes a stronger intent to RTW, which may explain the higher RTW rate. Job title among stroke survivors was studied by Saeki et al, ${ }^{23}$ who stated that white-collar workers were three times more likely to RTW than those in blue-collar occupations; in this study, there was no significant difference in time to full RTW between desk workers and manual workers. Other factors reported as predictors of RTW are younger age, good functional ability before hospital discharge, and office work. ${ }^{34}$

There have been no studies investigating the predictors of resignation among stroke survivors in Japan. Our study showed that participants 50 years and older had a shorter time to resignation than younger participants. It has been shown that older age is associated with a lower probability of RTW. ${ }^{18} 35$ We hypothesised that the 
Table 1 Participant characteristics and outcomes 365 days after the initial day of sickness absence due to stroke ( $n=380$ )

\begin{tabular}{|c|c|c|c|c|c|c|c|c|c|c|}
\hline Variables & $\mathbf{N}$ & $\begin{array}{l}1 \\
\text { Died } \\
\mathbf{N}\end{array}$ & $\begin{array}{l}2 \\
\text { Resigned } \\
\mathrm{N}\end{array}$ & $\begin{array}{l}3 \\
\text { Disabled } \\
\mathbf{N}\end{array}$ & $\begin{array}{l}4 \\
\text { RTW } \\
\mathrm{N}\end{array}$ & $\begin{array}{l}\text { Full } \\
\text { RTW } \\
\mathbf{N}\end{array}$ & $\begin{array}{l}\text { Partial } \\
\text { RTW } \\
\text { N }\end{array}$ & $\begin{array}{l}\text { Partial/full } \\
\text { RTW (ratio) }\end{array}$ & $\begin{array}{l}\text { Median time } \\
\text { to partial/full } \\
\text { RTW (days) }\end{array}$ & $\begin{array}{l}\text { Median time } \\
\text { to full RTW } \\
\text { (days) }\end{array}$ \\
\hline \multicolumn{11}{|l|}{ Age, years } \\
\hline$\leq 49$ & 96 & 3 & 3 & 13 & 77 & 14 & 63 & 4.5 & 97 & 180 \\
\hline$\geq 50$ & 284 & 6 & 23 & 49 & 206 & 55 & 151 & 2.7 & 108 & 276 \\
\hline \multicolumn{11}{|l|}{ Sex } \\
\hline Male & 332 & 8 & 22 & 52 & 250 & 62 & 188 & 3 & 98 & 245 \\
\hline Female & 48 & 1 & 4 & 10 & 33 & 7 & 26 & 3.7 & 134 & 352 \\
\hline \multicolumn{11}{|l|}{ Company size } \\
\hline$<1000$ employees & 30 & 0 & 0 & 4 & 26 & 5 & 21 & 4.2 & 97 & 178 \\
\hline$\geq 1000$ employees & 350 & 9 & 26 & 58 & 257 & 64 & 193 & 3 & 107 & 267 \\
\hline \multicolumn{11}{|l|}{ Company area } \\
\hline Rural & 111 & 3 & 7 & 16 & 85 & 23 & 62 & 2.7 & 99 & 220 \\
\hline Urban & 269 & 6 & 19 & 46 & 198 & 46 & 152 & 3.3 & 107 & 265 \\
\hline \multicolumn{11}{|l|}{ Desk worker/manual worker } \\
\hline Desk worker & 88 & 0 & 2 & 13 & 73 & 20 & 53 & 2.7 & 74 & 192 \\
\hline Manual worker & 292 & 9 & 24 & 49 & 210 & 49 & 161 & 3.3 & 118 & 273 \\
\hline \multicolumn{11}{|l|}{ Manager/non-manager } \\
\hline Non-manager & 358 & 9 & 24 & 62 & 263 & 63 & 200 & 3.2 & 107 & 268 \\
\hline Manager & 22 & 0 & 2 & 0 & 20 & 6 & 14 & 2.3 & 86 & 133 \\
\hline \multicolumn{11}{|l|}{ Stroke subtypes } \\
\hline Cerebral infarction & 196 & 4 & 9 & 19 & 164 & 43 & 121 & 2.8 & 67 & 174 \\
\hline Cerebral haemorrhage & 119 & 4 & 13 & 34 & 68 & 15 & 53 & 3.5 & 206 & \\
\hline Subarachnoid haemorrhage & 65 & 1 & 4 & 9 & 51 & 11 & 40 & 3.6 & 117 & 262 \\
\hline Total stroke & 380 & 9 & 26 & 62 & 283 & 69 & 214 & 3.1 & 106 & 259 \\
\hline
\end{tabular}


Table 2 Cox regression model for time to full-time return to work for the 365-day period following the initial day of sickness absence due to stroke

\begin{tabular}{|c|c|c|c|c|c|c|c|c|}
\hline \multirow[b]{2}{*}{ Variables } & \multicolumn{2}{|c|}{ Univariable analysis } & \multicolumn{2}{|l|}{ Model 1} & \multicolumn{2}{|l|}{ Model 2} & \multicolumn{2}{|l|}{ Model 3} \\
\hline & HR (95\% Cl) & p Value & HR (95\% Cl) & p Value & HR (95\% Cl) & p Value & HR (95\% Cl) & p Value \\
\hline \multicolumn{9}{|l|}{ Age, years } \\
\hline$\leq 49$ & 1 & & 1 & & & & 1 & \\
\hline$\geq 50$ & 0.81 (0.61 to 1.09 ) & 0.16 & 0.80 (0.59 to 1.08$)$ & 0.14 & & & 0.81 (0.61 to 1.09 ) & 0.16 \\
\hline \multicolumn{9}{|l|}{ Sex } \\
\hline Male & 1 & & 1 & & & & 1 & \\
\hline Female & 0.70 (0.46 to 1.06$)$ & 0.09 & 0.66 (0.42 to 1.03$)$ & 0.07 & & & 0.67 (0.43 to 1.04$)$ & 0.08 \\
\hline \multicolumn{9}{|l|}{ Company size } \\
\hline$\leq 999$ employees & 1 & & 1 & & & & & \\
\hline$\geq 1000$ employees & 0.78 (0.50 to 1.21$)$ & 0.27 & 0.96 (0.59 to 1.54$)$ & 0.86 & & & & \\
\hline \multicolumn{9}{|l|}{ Company area } \\
\hline Rural area & 1 & & 1 & & & & & \\
\hline Urban area & 0.89 (0.67 to 1.17$)$ & 0.40 & $0.82(0.60$ to 1.11$)$ & 0.20 & & & & \\
\hline \multicolumn{9}{|l|}{ Desk worker/manual worker } \\
\hline Desk worker & 1 & & 1 & & & & & \\
\hline Manual worker & 1.12 (0.83 to 1.52$)$ & 0.45 & $1.02(0.73$ to 1.41$)$ & 0.93 & & & & \\
\hline \multicolumn{9}{|l|}{ Manager/non-manager } \\
\hline Non-manager & 1 & & 1 & & 1 & & 1 & \\
\hline Manager & 1.81 (1.07 to 3.06$)$ & 0.02 & $1.67(0.99$ to 2.80$)$ & 0.05 & 1.71 (1.04 to 2.82$)$ & 0.04 & 1.68 (1.02 to 2.78 ) & 0.04 \\
\hline \multicolumn{9}{|l|}{ Stroke subtypes } \\
\hline Cerebral infarction & 1 & & 1 & & 1 & & 1 & \\
\hline Cerebral haemorrhage & 0.49 (0.36 to 0.68$)$ & $<0.01$ & 0.50 (0.36 to 0.68$)$ & $<0.01$ & 0.50 (0.36 to 0.69$)$ & $<0.01$ & 0.50 (0.36 to 0.69$)$ & $<0.01$ \\
\hline Subarachnoid haemorrhage & 0.76 (0.53 to 1.08$)$ & 0.12 & 0.88 (0.61 to 1.28$)$ & 0.51 & 0.86 (0.60 to 1.25$)$ & 0.43 & 0.85 (0.59 to 1.23$)$ & 0.40 \\
\hline
\end{tabular}




\begin{tabular}{|c|c|c|c|c|c|c|c|c|}
\hline & Univariable analysis & & Model 1 & & Model 2 & & Model 3 & \\
\hline Variables & HR (95\% Cl) & p Value & HR (95\% Cl) & p Value & HR (95\% Cl) & p Value & $\mathrm{HR}(95 \% \mathrm{Cl})$ & p Value \\
\hline \multicolumn{9}{|l|}{ Aqe, vears } \\
\hline$\leq 49$ & 1 & & 1 & & 1 & & 1 & \\
\hline$\geq 50$ & 2.94 (1.04 to 8.30$)$ & 0.04 & 2.89 (1.01 to 8.31$)$ & 0.05 & 3.30 (1.17 to 9.33$)$ & 0.02 & 3.31 (1.17 to 9.35$)$ & 0.02 \\
\hline \multicolumn{9}{|c|}{ 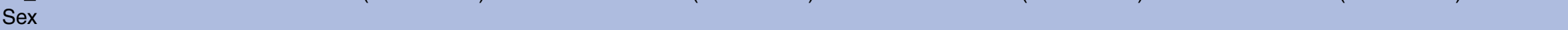 } \\
\hline Male & 1 & & 1 & & & & 1 & \\
\hline Female & $1.36(0.57$ to 3.26$)$ & 0.49 & $1.23(0.48$ to 3.13$)$ & 0.67 & & & 1.16 (0.48 to 2.79$)$ & 0.74 \\
\hline \multicolumn{9}{|l|}{ Company size } \\
\hline$\leq 999$ employees & 1 & & 1 & & & & & \\
\hline$\geq 1000$ employees & 3.19 (0.44 to 23.26$)$ & 0.25 & 2.75 (0.37 to 20.70$)$ & 0.33 & & & & \\
\hline \multicolumn{9}{|l|}{ Company area } \\
\hline Rural area & 1 & & 1 & & & & & \\
\hline Urban area & $1.10(0.53$ to 2.27$)$ & 0.80 & 0.99 (0.46 to 2.13$)$ & 0.99 & & & & \\
\hline \multicolumn{9}{|l|}{ Desk worker/manual work } \\
\hline Desk worker & 1 & & 1 & & 1 & & 1 & \\
\hline Manual worker & 0.27 (0.82 to 0.87$)$ & 0.03 & $0.26(0.77$ to 0.89$)$ & 0.03 & 0.24 (0.07 to 0.78$)$ & 0.02 & 0.24 (0.07 to 0.80$)$ & 0.02 \\
\hline \multicolumn{9}{|l|}{ Manager/non-manager } \\
\hline Non-manager & 1 & & 1 & & & & & \\
\hline Manager & $0.96(0.23$ to 4.00$)$ & 0.95 & $1.18(0.27$ to 5.05$)$ & 0.83 & & & & \\
\hline \multicolumn{9}{|l|}{ Stroke subtypes } \\
\hline Cerebral infarction & 1 & & 1 & & & & & \\
\hline Cerebral haemorrhage & 2.19 (1.09 to 4.41$)$ & 0.03 & $1.92(0.95$ to 3.89$)$ & 0.07 & & & & \\
\hline Subarachnoid haemorrhage & $1.05(0.38$ to 2.90$)$ & 0.93 & $0.94(0.32$ to 2.75$)$ & 0.91 & & & & \\
\hline
\end{tabular}


number of years of occupational life remaining after experiencing a stroke may strongly influence the intent to resign. As 'resignation' in this study includes leaving work because of retirement, it is only natural that older age is a predictor of shorter time to resignation. Contrary to our predictions, desk workers had a shorter time to resignation, and we were unable to provide an explanation for this observation.

Decision of partial or full RTW was not based on an objective standard, rather, it was entirely based on the OPs' subjective judgement. In general, RTW for stroke survivors is quite complex, and depends on a variety of medical and non-medical factors. ${ }^{16}$ In the present study, OPs were assumed to have an understanding of the disease-specific information of each participant for their RTW, and the decision of partial RTW may be associated with findings of a worsened prognosis.

\section{Strengths, limitations and implications}

One of the strengths of the present study was the enrolment of a large group of participants; approximately 400 Japanese employees who experienced a period of sickness absence due to stroke were included in this, the first large-scale Japanese RTW study of stroke survivors. Additionally, the follow-up rate was quite high (nearly $100 \%)$. With this system, there was less participant selection and loss to follow-up biases that may have possibly affected other studies. Furthermore, we used an objective measurement of sickness absence; the present study was based on data from clinically certified sickness absence using physicians' certificates. Utilisation of clinically made ICD-10 diagnoses of the participants' single episode of stroke allowed for higher validity and reliability than categorisation by other diseases, such as psychiatric diseases.

Several limitations should be noted when interpreting the results of the present study. First, the medical information of the participants was not available for use in the present study, such as stage of stroke, or type of treatment. The cumulative RTW rate of stroke survivors can be affected by clinical findings such as severity of stroke, daily living status, mental impairment, etc, although stroke location has been shown to be not associated with RTW after the patient's first ischaemic stroke. ${ }^{11} 203637$ Saeki $e t$ al reported that the process of RTW is quite variable between individuals, and can be affected by a number of factors. ${ }^{38}$ However, in the present study, cumulative RTW rates according to stroke subtype were calculated. Second, we could not deny the existence of comorbidities in the participants, due to the registration of only one diagnosis per episode of sickness absence by the OPs. Participants may have had other disorders during the sickness absence, such as depression or ileus after iliac surgery, or other symptoms such as depressive mood, anxiety, or sleep disorders, often found in stroke survivors. Knowledge of comorbidities is necessary due to their influence on time to RTW. Third, no differentiation was made for participants who may have had stroke prior to working at the company in question. Fourth, because the majority of the participants were male, caution should be taken for generalisations across the entire workforce based on the present results. Fifth, the participants did not include employees working in small-sized and medium-sized enterprises, which raises a question about the representativeness of the stroke survivors in the sample. People working for themselves or for smaller employers seem to have less 'protection' in terms of the capacity of the employer or company to make 'reasonable adjustments' to accommodate a RTW. ${ }^{39}$ Therefore these factors (enterprise size and type of employment) will influence RTW outcome success. Sixth, the initial date of sickness absence may have been different from the date of diagnosis, or the date of the start of the illness.

This type of study may help companies establish and improve their RTW support system for stroke survivors, and improvements in healthcare policies may provide greater support and satisfaction for stroke survivors' and their families. ${ }^{13}$ Organisational RTW support is very important for facilitating RTW for workers with longterm sickness leave. ${ }^{40}$ Future studies should investigate, in more detail, predictors of recurrent sickness absence after RTW to mediate drafting of a strategy for RTW support for employees who have had a stroke. Possible factors underlying recurrent sickness absence after RTW may include recurrent stroke, as well as may take into account psychiatric disorders such as depression and anxiety disorders, or fracture, acute myocardial infarction, etc. Research on mental health problems may be important for the improvement of quality of life for stroke survivors.

\section{CONCLUSION}

The cumulative full RTW rates at $60,120,180$ and 365 days were $15.1 \%, 33.6 \%, 43.5 \%$ and $62.4 \%$, respectively; these rates depended on the subtype of stroke. 'Older age' and 'non-manual worker' were identified as predictors of resignation. Occupational health professionals may be better able to support patients with stroke for RTW with the knowledge that cumulative RTW rates vary by subtype of stroke, referring to the Kaplan-Meier curve presented in this study.

Contributors TS and YS advised on statistical analysis and making tables. $\mathrm{YH}, \mathrm{NK}$ and RK made research plans for this study, collected previous studies and reviewed the manuscript. NY supervised, and was adviser for this study.

Funding This research received no specific grant from any funding agency in the public, commercial or not-for-profit sectors.

Competing interests None declared.

Ethics approval The protocol of this cohort study was approved by the Medical Ethics Committee of Tokyo Women's Medical University (number: 3244).

Provenance and peer review Not commissioned; externally peer reviewed.

Data sharing statement No additional data are available. 
Open Access This is an Open Access article distributed in accordance with the Creative Commons Attribution Non Commercial (CC BY-NC 4.0) license, which permits others to distribute, remix, adapt, build upon this work noncommercially, and license their derivative works on different terms, provided the original work is properly cited and the use is non-commercial. See: http:// creativecommons.org/licenses/by-nc/4.0/

\section{REFERENCES}

1. Arauz A. Return to work after stroke: the role of cognitive deficits. J Neurol Neurosurg Psychiatry 2013;84:240.

2. Irie $\mathrm{F}, \mathrm{Kamouchi} \mathrm{M}$, Hata $\mathrm{J}$, et al. Sex differences in short-term outcomes after acute ischemic stroke: the Fukuoka Stroke Registry. Stroke 2015;46:471-6.

3. Gilworth G, Phil M, Cert A, et al. Personal experiences of returning to work following stroke: an exploratory study. Work 2009;34:95-103.

4. Doucet T, Muller F, Verdun-Esquer C, et al. Returning to work after a stroke: a retrospective study at the Physical and Rehabilitation Medicine Center La Tour de Gassies. Ann Phys Rehabil Med 2012;55:112-27.

5. Ministry of Health, Labour and Welfare. Vital Statistics. 2011.

6. Iso H. Lifestyle and cardiovascular disease in Japan. $J$ Atheroscler Thromb 2011;18:83-8.

7. Luengo-Fernandez R, Gray AM, Rothwell PM. Costs of stroke using patient-level data: a critical review of the literature. Stroke 2009;40: e18-23.

8. Feigin VL. Stroke in developing countries: can the epidemic be stopped and outcomes improved? Lancet Neurol 2007;6:94-7.

9. Brown DL, Boden-Albala B, Langa KM, et al. Projected costs of ischemic stroke in the United States. Neurology 2006;67:1390-5.

10. Harris C. Return to work after stroke: a nursing state of the science. Stroke 2014;45:e174-6.

11. Tanaka $\mathrm{H}$, Toyonaga $\mathrm{T}$, Hashimoto $\mathrm{H}$. Functional and occupational characteristics associated with very early return to work after stroke in Japan. Arch Phys Med Rehabil 2011:92:743-8.

12. Saeki S. Disability management after stroke: its medical aspects for workplace accommodation. Disabil Rehabil 2000;22:578-82.

13. Singhal AB, Lo W. Life after stroke: beyond medications. Neurology 2014;83:1128-9.

14. Persson J, Ferraz-Nunes J, Karlberg I. Economic burden of stroke in a large county in Sweden. BMC Health Serv Res 2012;12:341.

15. Wolf TJ, Baum C, Conner LT. Changing face of stroke: implications for occupational therapy practice. Am J Occup Ther 2009;63:621-5.

16. Saeki S, Hachisuka K. The association between stroke location and return to work after first stroke. J Stroke Cerebrovasc Dis 2004;13:160-3.

17. Hannerz H, Pedersen BH, Poulsen OM, et al. Study protocol to a nationwide prospective cohort study on return to gainful occupation after stroke in Denmark 1996-2006. BMC Public Health 2010;10:623.

18. Hannerz H, Holbaek Pedersen B, Poulsen OM, et al. A nationwide prospective cohort study on return to gainful occupation after stroke in Denmark 1996-2006. BMJ Open 2011;1:e000180.

19. Saeki S, Toyonaga T. Determinants of early return to work after first stroke in Japan. J Rehabil Med 2010;42:254-8.

20. Kauranen $\mathrm{T}$, Turunen $\mathrm{K}$, Laari $\mathrm{S}$, et al. The severity of cognitive deficits predicts return to work after a first-ever ischaemic stroke. J Neurol Neurosurg Psychiatry 2013;84:316-21.
21. Perk J, Alexanderson K. Swedish Council on Technology Assessment in Health Care (SBU). Chapter 8. Sick leave due to coronary artery disease or stroke. Scand J Public Health Suppl 2004:63:181-206.

22. Glozier N, Hackett ML, Parag V, et al. The influence of psychiatric morbidity on return to paid work after stroke in younger adults: the Auckland Regional Community Stroke (ARCOS) Study, 2002 to 2003. Stroke 2008;39:1526-32.

23. Saeki S, Ogata H, Okubo T, et al. Factors influencing return to work after stroke in Japan. Stroke 1993;24:1182-5.

24. Busch MA, Coshall C, Heuschmann PU, et al. Sociodemographic differences in return to work after stroke: the South London Stroke Register (SLSR). J Neurol Neurosurg Psychiatry 2009;80:888-93.

25. Hannerz H, Mortensen OS, Poulsen OM, et al. Time trend analysis of return to work after stroke in Denmark 1996-2006. Int J Occup Med Environ Health 2012;25:200-4.

26. Daniel K, Wolfe CD, Busch MA, et al. What are the social consequences of stroke for working-aged adults? A systematic review. Stroke 2009;40:e431-40.

27. Treger I, Shames J, Giaquinto S, et al. Return to work in stroke patients. Disabil Rehabil 2007:29:1397-403.

28. Hannerz H, Ferm L, Poulsen OM, et al. Enterprise size and return to work after stroke. J Occup Rehabil 2012:22:456-61.

29. Hensing G. Swedish Council on Technology Assessment in Health Care (SBU). Chapter 4. Methodological aspects in sickness-absence research. Scand J Public Health Suppl 2004;63:44-8.

30. Christensen KB, Andersen PK, Smith-Hansen L, et al. Analyzing sickness absence with statistical models for survival data. Scand $J$ Work Environ Health 2007:33:233-9.

31. Kelly PJ, Furie KL, Shafqat $\mathrm{S}$, et al. Functional recovery following rehabilitation after hemorrhagic and ischemic stroke. Arch Phys Med Rehabil 2003;84:968-72.

32. Nishino A, Sakurai Y, Tsuji I, et al. Resumption of work after aneurysmal subarachnoid hemorrhage in middle-aged Japanese patients. J Neurosurg 1999;90:59-64.

33. Netterstrøm B, Bech P. Effect of a multidisciplinary stress treatment programme on the return to work rate for persons with work-related stress. A non-randomized controlled study from a stress clinic. BMC Public Health 2010;10:658.

34. Howard G, Till JS, Toole JF, et al. Factors influencing return to work following cerebral infarction. JAMA 1985;253:226-32.

35. Wozniak MA, Kittner SJ. Return to work after ischemic stroke: a methodological review. Neuroepidemiology 2002;21:159-66.

36. Hackett ML, Glozier N, Jan S, et al. Returning to paid employment after stroke: the Psychosocial Outcomes In StrokE (POISE) cohort study. PLOS ONE 2012;7:e41795.

37. Wozniak MA, Kittner SJ, Price TR, et al. Stroke location is not associated with return to work after first ischemic stroke. Stroke 1999;30:2568-73

38. McCluskey A, Vratsistas-Curto A, Schurr K. Barriers and enablers to implementing multiple stroke guideline recommendations: a qualitative study. BMC Health Serv Res 2013;13:323.

39. Moriguchi J, Ikeda M, Sakuragi S, et al. Activities of occupational physicians for occupational health services in small-scale enterprises in Japan and in the Netherlands. Int Arch Occup Environ Health 2010;83:389-98.

40. Sampere M, Gimeno D, Serra C, et al. Organizational return to work support and sick leave duration: a cohort of Spanish workers with a long-term non-work-related sick leave episode. J Occup Environ Med 2011;53:674-9. 